\title{
Perfil Cromatográfico e Avaliação da Atividade Antimicrobiana de Diferentes Extratos de Pupunha (Bactris gasipaes, Kunth)
}

\section{Chromatographic Profile and Evaluation of Antimicrobial Activity of Different Peach Palm Extracts (Bactris gasipaes, Kunth)}

\author{
Gerodes Vasconcelos da Costa*a; Waldireny Caldas Rocha; Adriana Dantas Gonzaga de Freitas ${ }^{\mathrm{a}}$
}

Universidade Federal do Amazonas, AM, Brasil.

*E-mail: gerodesvasconcelos5@gmail.com

\begin{abstract}
Resumo
As plantas têm sido utilizadas como um importante recurso para sociedade, por possuir propriedades biológicas e químicas. Espécies vegetais oleaginosas estão sendo alvo de diversos trabalhos para estudar o potencial de seus extratos como matéria-prima para elaboração de diversos produtos. Entre essas espécies se destaca a pupunheira (Bactris gasipaes, Kunth). O presente trabalho teve por objetivo avaliar o potencial biológico de diferentes extratos oriundos de frutos da pupunha. Os extratos da pupunha foram obtidos a partir de extratores do tipo Soxhlet, utilizando metanol e hexano como solvente. Os maiores rendimentos obtidos foram de cerca de $27 \%$ a $25 \%$ extratos para a extração da casca e da polpa do fruto respectivamente. A atividade antimicrobiana foi avaliada em cepas de Escherichia coli (ATCC25922), Staphylococcus aureus (ATCC25923) e Klebsiella pneumoniae (ATCC700603), por meio da técnica de disco difusão. Foram obtidos resultados negativos para algumas amostras de extratos do caroço e positivos para polpa e da casca. Os resultados obtidos demonstram potencial para a presença de substâncias nos extratos analisados com potencial atividade antioxidante e antimicrobiana na pupunha e estes resultados colaboram para novas investigações, e formulações de produtos biotecnológicos envolvendo extratos da pupunha amazônica.
\end{abstract}

Palavras-chave: Perfil Cromatográfico. Atividade Antimicrobiana. Pupunheira. DPPH/TLC.

\begin{abstract}
Plants have been used as an important resource for the society, as they have biological and chemical properties. Oilseed plant species are the target of several studies that evaluate the potential of their extracts as raw material for various products. Among these species, the peach palm (Bactris gasipaes, Kunth) stands out. The present work aimed to evaluate the biological potential of different extracts from pupunha fruits. The pupunha extracts were obtained from Soxhlet extractors, using methanol and hexane as solvent. The highest yields obtained were about 27\% to $25 \%$ extracts for the extraction of the peel and pulp of the fruit respectively. Antimicrobial activity was evaluated in strains of Escherichia coli (ATCC25922), Staphylococcus aureus (ATCC25923) e Klebsiella pneumoniae (ATCC700603), using the disk diffusion technique. Negative results were obtained for some samples of core extracts and positive for pulp and peel, after taking the mean and standard deviation of the diameters of the formed halos. The results obtained demonstrate the potential for the presence of substances in the analyzed extracts with potential antioxidant and antimicrobial activity in pupunha and these results collaborate for further investigations, and formulations of biotechnological products involving extracts from the Amazonian pupunha.
\end{abstract}

Keywords: Cromatography Profile. Antimicrobial Activity. DPPH/TLC

\section{Introdução}

Desde início da humanidade, as plantas têm sido utilizadas como um importante recurso para sociedade, como fontes de nutrientes e de produtos naturais, sendo cruciais para o desenvolvimento de vários produtos por apresentar variadas classes com interesses científicos em função de suas propriedades biológicas e químicas (CAVALCANTI FILHO, 2014; GIORDANI et al, 2008).

O Brasil detém cerca de $20 \%$ da diversidade biológica mundial (SUDAM, 1995; SOUZA et al., 2004) e uma parcela considerável desta biodiversidade está localizada nos ecossistemas Amazônicos. Porém, mesmo possuindo uma grande diversidade biológica, poucos estudos foram apresentados em relação à quantidade de espécies com potencial biotecnológico presentes nas florestas da Amazônia (NODORI; GUERRA, 2004).
A busca por agentes antimicrobianos tem sido um ponto crucial em vários setores do campo farmacêutico e cosmético. Estudo desta natureza é ponto de partida para a descoberta de novos produtos biotecnológicos e contribuem, significativamente, no desenvolvimento do campo da saúde em nível mundial, podendo detectar substâncias mais eficazes e menos tóxica na corrida contra a resistência de micro-organismos patogênicos, porém a busca por novos antimicrobianos é uma tarefa árdua e difícil (OSTROSKY et al., 2008).

Atualmente, as espécies vegetais oleaginosas estão sendo alvo de diversos trabalhos, que vem comprovando a eficiência como agente antimicrobiano. Entre essas espécies se destaca a pupunheira (Bactris gasipaes, Kunth), que possui frutos que são usados na economia tanto urbana como rural. Seu uso pode se dar na forma de farinha, bebida fermentada e fruto cozido, que são importantes na alimentação por apresentar 
um elevado valor nutritivo e energético (CLEMENT, 2000; YUYAMA; COZZOLINO, 1996; CARVALHO et al., 2009; OLIVEIRA, 2003; SODRE, 2014).

Logo, este trabalho teve como objetivo avaliar os constituintes químicos e a atividade antimicrobiana dos extratos metanólicos e hexanicos dos frutos da pupunheira (Bactris gasipaes Kunth), bem como analisar o perfil cromatográfico e a atividade antioxidante dos extratos da pupunha.

\section{Material e Métodos}

\subsection{Obtenção das pupunhas}

Os frutos foram coletados no Centro de Apoio à Pesquisa do Médio Solimões da Universidade Federal do Amazonas, ISB-UFAM, no período de abril a maio de 2016. Dez amostras foram colhidas no horário matutino e devidamente higienizados com água corrente no Laboratório de Química Orgânica do ISB. Os frutos foram então divididos em casca, polpa e caroço e cada parte foi pesada. Posteriormente, foram colocados em estufa de secagem a uma temperatura de $40^{\circ} \mathrm{C}$ para a desidratação por um período de sete dias.

\subsection{Obtenção do extrato}

Cada parte do fruto desidratado foi submetido à extração com solventes orgânicos. Cada parte do fruto $(500 \mathrm{~g})$ foi extraído com os seguintes solventes: casca (metanol), polpa (hexano) e caroço (hexano e metanol). Foram utilizados $500 \mathrm{~mL}$ do solvente em cada extração. Para o preparo dos extratos da pupunha, foi utilizado um extrator do tipo Soxhlet. As amostras foram colocadas em cartucho de papel filtro e pesadas. Cada cartucho de 500g foi colocado no aparelho e adicionado o solvente. Após 15 a 20 refluxos foi observado descoramento do solvente e a extração foi finalizada. $\mathrm{O}$ líquido extrator resultante foi levado para uma capela para a eliminação do solvente. Os extratos obtidos foram transferidos para um dessecador de vidro com sílica ativada por sete dias, para a retirada da umidade e pesadas até manter um peso constante.

\subsection{Rendimento dos extratos}

Para o rendimento do extrato da pupunha, foi realizada a pesagem da casca, da polpa e semente em balança analítica (500 g) e, depois, de submetida à extração. Após secagem todos os extratos foram pesados e, em seguida, foi calculado o rendimento final expresso em porcentagem $(\%)$, conforme a metodologia utilizada por Figueiredo (2018).

\subsection{Perfil cromatográfico dos extratos por TLC-CCD}

Para obtenção do perfil cromatográfico dos extratos de pupunha, foi preparado uma solução de $10 \mathrm{mg} / \mathrm{mL}$ de cada e aplicado com o auxílio de uma seringa de vidro, uma alíquota de $5 \mu \mathrm{L}$ de cada extrato, em forma de bandas de $0,8 \mathrm{~mm}$, em placas cromatográficas de fase normal com tamanhos variados com ajuda de um equipamento automático de aplicação de bandas do tipo Linomat 5 produzido pela CAMAG ${ }^{\circledR}$. Nesta análise, foi realizada a cromatografia em camada delgada (CCD), utilizando placas cromatográficas de fase normal de gel de sílica com indicador de florescência. Foram testados diferentes sistemas para eluição seguindo a ordem crescente de polaridade com o objetivo de se encontrar um sistema, que promovesse a separação cromatográfica. Os eluentes foram preparados, conforme a natureza da amostra, visando melhor separação cromatográfica, conforme descrito por Figueiredo (2018).

\subsection{Revelações Cromatográfica}

As placas cromatográficas foram observadas e fotodocumentados em um equipamento TLC visualizer CAMAG $^{\circledR}$ com comprimento de onda de 256 e 366 $\mathrm{nm}$. Em seguida, as placas foram reveladas com solução de ácido fosfomolibidínico e de vanilina sulfúrica por imersão seguida de aquecimento. Os extratos em metanol das polpas foram revelados ainda com solução NP e PEG (difenilboriloxietilamina/polietilenoglicol) para indicar a presença de flavonoides presente nas amostras, logo após foram visualizadas em uma câmara de luz ultravioleta (UV), para observar as separações das bandas nas placas.

\subsection{Análise da atividade antioxidante em DPPH}

Os extratos foram avaliados com relação a sua capacidade de captura de radical livre estável 2,2'-difenil-1-picrilhidrazila (DPPH), por Cromatografia em Camada Delgada (CCD) segundo método de Blois (1958).

Para avaliar a atividade antioxidade, foi diluído 10 e $50 \mathrm{mg}$ de cada extrato do fruto da pupunha em $5 \mathrm{~mL}$ de diclorometano, visando melhor diluição dos extratos foi utilizado um equipamento de banho ultrassom de $60 \mathrm{KHz}$ de frequência.

Após a diluição, os extratos foram aplicados em placa cromatográfica de fase normal com capilar de vidro em forma de banda. Como controle positivo foi utilizado uma solução metanólica de ácido ascórbico na concentração de $1 \mathrm{mg} / \mathrm{mL}$. As placas foram imersas em uma solução metanólica de DPPH na concentração de $2 \%$ e envolvidas em papel alumínio. Depois de trinta minutos, foi realizada a leitura da placa, em que halos amarelados sobre fundo de coloração púrpura, são considerados positivos. Este ensaio foi realizado no Laboratório de Micologia do Departamento de Parasitologia do Instituto de Ciências Biológica (ICB) da UFAM.

\subsection{Avaliação da atividade antimicrobiana}

Os testes foram realizados no Laboratório de Pesquisa em Microbiologia- UFAM, no qual foram analisadas três cepas de cepas bacterianas de padrões internacionais (ATCCAmerican Type Culture Colletion) sendo essas: Escherichia coli (ATCC 25922), Staphylococcus aureus (ATCC 25923), 


\section{Klebsiella pneumoniae (ATCC13899).}

Os isolados foram cultivados em tubos de ensaio pequenos, contendo $20 \mathrm{ml}$ do meio Ágar Triptona de Soja (TSA), incubadas em estufa a $28^{\circ} \mathrm{C}$ por 24 horas. As suspensões das culturas microbianas foram preparadas a partir de colônias isoladas das cepas reativadas a $10^{8} \mathrm{UFC} / \mathrm{ml}$.

Três diferentes concentrações de extratos $(25,50,75$ e 10 $\mathrm{mg} / \mathrm{mL}$ ) foram obtidas a partir da diluição em $1000 \mu \mathrm{L}$ de dimetilsulfóxido (DMSO) em microtubos esterilizados com tampa. O controle do diluente foi preparado a partir de uma solução aquosa de DMSO a 20\%.

Posteriormente, as culturas foram semeadas sobre a superfície da placa, contendo $20 \mathrm{~mL}$ de BDA com o auxílio de um Swab estéril. Foram adicionados sob o BDA discos de 6,0 mm de diâmetros, que foram impregnados com $10 \mu \mathrm{L}$ dos extratos do fruto da pupunha nas diferentes concentrações obtidas. Os ensaios foram realizados em triplicata.

As placas ficaram sobre refrigeração $\left(28^{\circ} \mathrm{C}\right)$ por um período de quatro horas. Em seguida, foram incubadas em uma estufa tipo B.O.D (Biological Oxygen Demand) a $37^{\circ} \mathrm{C}$ por sete dias, com a medição dos halos de inibição ao término deste tempo.

\section{Resultados e Discussão}

\subsection{Obtenção dos extratos das amostras de pupunha}

As extrações foram realizadas em etapas, obtendo extratos de coloração e texturas diferentes. Segundo Zuanazzi e Montanha (2003), salienta-se que extração com solventes de alta e baixa polaridade, como o hexano e metanol, tem a capacidade de retirar as substâncias com polaridades diferentes. Os extratos do fruto da pupunha apresentaram rendimentos variados, em função da quantidade de amostra usada na extração, porém a proporção usada não influenciou no processo de extração, pois foi possível obter uma quantidade considerável de extrato das amostras de caroço. Foram obtidos nove extratos de diferentes partes do fruto da pupunha, da polpa, da casca e do caroço.

O melhor rendimento dos extratos de hexano da polpa do fruto variaram de $26,97 \%$ a $7,56 \%$ para as amostras 1 e 2 de polpa extraídas. Foi observado o rendimento de $8,85 \%$ da amostra 4 com rendimento maior que da amostra 2 , em decorrência da quantidade de material extraído da polpa do fruto. Céo, Silva e Pinto (2010), em trabalho com o teor de normalidade do fruto da pupunha, obtiveram rendimento de média de $22,83 \%$ de óleo na polpa seca, em que o tamanho do fruto pode variar de 10 a 200 gramas. Estudos realizados por Arkcoll e Aguiar (1984) revelaram um rendimento de 62\% de óleo do mesocarpo de pupunha e $34 \%$ de óleo em relação ao peso do cacho.

Os rendimentos dos extratos metanólicos da casca foram de $14,18 \%, 1,67 \%, 25,16 \%$. Constatou-se que após o processo de extração do caroço, esses proporcionaram rendimento muito baixo. Os rendimentos dos extratos hexanólicos e metanólicos do caroço foram de, 1,47\% e 7,88.

Existem diversos fatores que podem influenciar no processo do rendimento ou até mesmo na forma da amostra extraída, tais como: o método de extração, o solvente empregado, a temperatura, o tempo de extração, a amostra utilizada, o tamanho das partículas do material vegetal processado, quanto menor o tamanho das partículas do material vegetal, o solvente pode atuar em maior contato com a área superficial (LAROZE; SOTO; ZÚÑIGA, 2010; ROCKENBACH et al., 2008; BIMAKR et al., 2011). A composição pode variar de acordo com fatores ambientais, como manejo das plantas, forma de extração e armazenamento (NASCIMENTO et. al. 2007). As diferenças observadas na extração com solventes de polaridade alta e baixa apresentaram amostras com rendimentos variados, fornecendo um percentual consideravelmente satisfatório que permitiu realizar este estudo.

\subsection{Perfil cromatográfico}

Para as análises cromatográficas, foram testadas diversas concentrações de solvente até se chegar a mais apropriada para a separação das substâncias, que compõem cada amostra. Foram aplicados $5 \mu \mathrm{L}$ de cada extrato. A fase móvel utilizada foi uma mistura de tolueno e acetato de atila, na proporção 7:3.

Os extratos e frações correspondentes à polpa da pupunha apresentaram o comportamento exibido na Figura 1, na qual pode se observar as substâncias majoritárias presentes em cada extrato.

Figura 1 - Perfil cromatográfico do extrato hexanólicos da polpa da pupunha. (A) luz branca, (B) UV $254 \mathrm{~nm}$, (C) luz UV $366 \mathrm{~nm}$, (D) vanilina sulfúrica. Fase móvel tolueno/acetato (7:3 v/v)

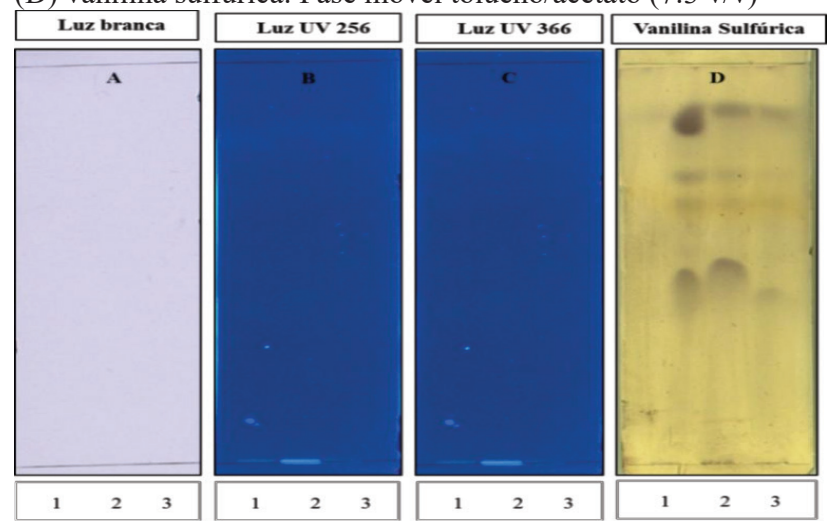

Fonte: Dados da pesquisa.

Com relação à placa cromatográfica revelada em vanilina sulfúrica (Figura 1D), que é considerado um revelador universal, houve uma melhor revelação na qual foi possível notar a presença da substância majoritária. $\mathrm{O}$ fator de retenção (Rf) de cada banda observada foi medido pelo software WinCATS.

As frações das amostras da casca do fruto da pupunha não se tornaram visíveis quando utilizada a luz UV com comprimento de onda $254 \mathrm{~nm}$, contudo em luz UV com comprimento de onda de $366 \mathrm{~nm}$, a fração um da amostra 2 da 
casca foi a que houve uma boa separação dos componentes, tornou visível em luz UV. Já a revelação em vanilina sulfúrica tornou as frações visíveis, permitindo realizar os cálculos dos valores de Fator de retenção Rf das amostras aplicadas.

Lima (2014) descreve que o revelador vanilina sulfúrica é considerado um revelador universal por conseguir indicar grande parte das classes químicas existentes, classificados como princípios amargos.

Figura 2 - Perfil cromatográfico do extrato metanólicos das amostras de casca do fruto da pupunha. Fase móvel tolueno/ acetato $(7: 3 \mathrm{v} / \mathrm{v})$. Placa visualizada em luz UV e revelada com reagente: (A) luz branca, (B) UV $254 \mathrm{~nm}$, (C) luz UV $366 \mathrm{~nm}$, (D) vanilia sulfúrica

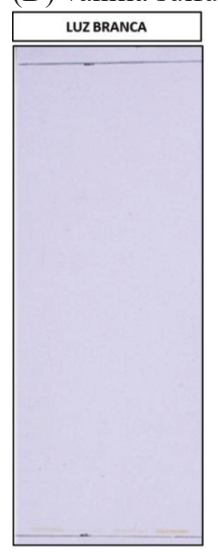

$\begin{array}{llll}1 & 2 & 3 & 4\end{array}$ Fonte: Dados da pesquisa.

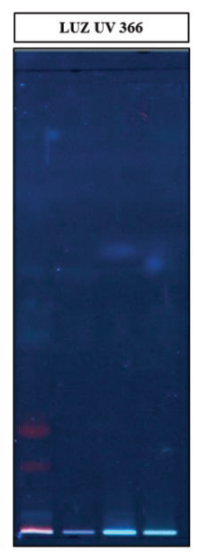

$\begin{array}{llllllll}1 & 2 & 3 & 4 & 1 & 2 & 3 & 4\end{array}$

Na placa com fração de extratos hexanólicos e metanólicos do caroço foi possível observar a presença de bandas de cor amareladas. Contudo, a revelação com vanilina sulfúrica demonstrou melhor visualização do fator de retenção das placas das frações cromatográficas em relação à luz UV, pois as amostras do perfil cromatográfico com as substâncias do caroço não se tornaram visíveis quando utilizada a luz UV com comprimento de onda 254 e $366 \mathrm{~nm}$.

Figura 3 - Perfil cromatográfico do extrato metanólicos e hexanólicos do caroço do fruto da pupunha. Placa visualizada em luz UV e revelada com reagente: (A) luz branca, (B) UV $254 \mathrm{~nm}$, (C) luz UV 366 nm, (D) vanilina sulfúrica
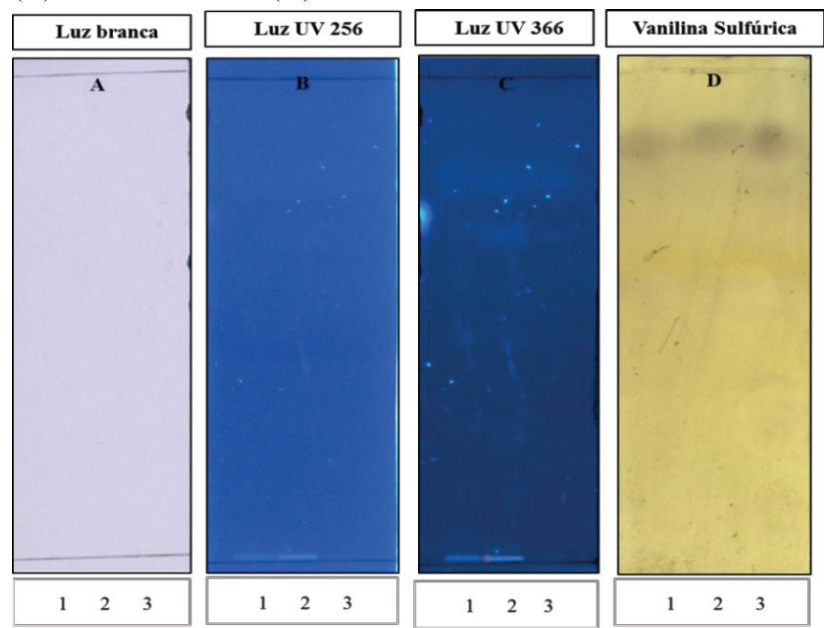

Fonte: Dados da pesquisa.
As placas cromatográficas eluídas, em sistema tolueno e acetato de atila, devidamente saturado, apresentaram o fator de retenção favorável para as frações aplicadas nas amostras cromatográficas. O preparo das frações e aplicações no sistema ideal de polaridade alta ou baixa são fatores de grande importância para a divisão dos constituintes de uma amostra na CCD.

Restrepo, Estupiñán e Colmenares (2016) revelam que em análise cromatográfica do extrato lipídico de Bactris gasipaes indicam uma composição de ácidos graxos insaturados comparável ao azeite e outras sementes oleaginosas comerciais, quanto ao teor de ácidos oleicos linoleicos e linolênicos.

\subsection{Atividade antioxidante DPPH}

Os resultados obtidos por meio do método antioxidante DPPH mostraram resultados positivos nas amostras dos extratos metanólicos e hexanólicos das partes dos frutos da pupunheira. Isto ficou evidenciado nas cromatoplacas em função da presença de manchas amarelas sobre funda púrpura, quando reveladas por DPPH, indicando a presença de antioxidantes.

O teste com DPPH é um método bastante conveniente para a varredura da atividade antioxidante de pequenas moléculas, uma vez que a reação com as substâncias pode ser observada em luz branca (SÁNCHEZ-MORENO, 1998).

\subsection{Atividade antimicrobiana}

Os extratos das amostras 1 e 4 da polpa do fruto da pupunheira frente às cepas de Escherichia coli apresentaram formação de halo de inibição em todas as concentrações testadas (Tabela 1). As demais amostras não apresentaram resultados promissores frente ao crescimento bacteriano.

Para a inibição do crescimento de Staphylococcus aureus, os resultados foram favoráveis para amostras 1 e 2 (6 mm). Todas as concentrações aplicadas das duas amostras apresentaram valores com maior ação inibitória frente ao crescimento do micro-organismo. Já para o extrato 4 da polpa não foi detectada a presença de formação de halo. Os valores para as diluições de $25 \mathrm{mg}$, $50 \mathrm{mg}, 75 \mathrm{mg}$ e $100 \mathrm{mg}$ foi inferior as amostras 1 e 2 dos extratos. Os resultados do diâmetro dos halos de inibição estão apresentados no Quadro 1. 
Quadro 1 - Valores dos diâmetros dos halos de inibição em milímetros do teste da atividade antimicrobiana dos extratos da pupunha, frente bactérias Escherichia coli, Staphylococus aureus e Klebsiella pneumoniae conforme o teste Tukey a 5\% de significância

\begin{tabular}{|c|c|c|c|c|}
\hline \multicolumn{5}{|c|}{ Micro-organismos } \\
\hline Amostras & $\begin{array}{c}\text { Concentração } \\
(\mathrm{mg} / \mathrm{mL})\end{array}$ & E.coli & S. aureus & $\begin{array}{c}\text { K. pneu- } \\
\text { moniae }\end{array}$ \\
\hline \multirow{4}{*}{ Polpa 1} & 25 & $0,8 \pm 0,04$ & $0,3 \pm 0,3$ & $0,7 \pm 0,04$ \\
\hline & 50 & $0,8 \pm 0,08$ & $0,8 \pm 0,04$ & $0,6 \pm 0,04$ \\
\hline & 75 & $0,8 \pm 0,2$ & $0,8 \pm 0,04$ & $0,7 \pm 1,1$ \\
\hline & 100 & $0,9 \pm 0,44$ & $0,6 \pm 0,4$ & $0,7 \pm 0,04$ \\
\hline \multirow{4}{*}{ Polpa 2} & 25 & $0,3 \pm 0,3$ & $0,2 \pm 0,3$ & $0,6 \pm 0,04$ \\
\hline & 50 & $0,2 \pm 0,3$ & $0,6 \pm 0,4$ & $0,7 \pm 0,06$ \\
\hline & 75 & $0,3 \pm 0,4$ & $0,6 \pm 0,4$ & $0,8 \pm 1,1$ \\
\hline & 100 & - & $0,6 \pm 0,4$ & $0,8 \pm 0,08$ \\
\hline \multirow{4}{*}{ Polpa 4} & 25 & $0,9 \pm 0,8$ & $0,4 \pm 0,3$ & $0,7 \pm 0,04$ \\
\hline & 50 & $0,7 \pm 0,6$ & $0,3 \pm 0,3$ & $0,8 \pm 0,04$ \\
\hline & 75 & $0,5 \pm 0,3$ & $0,5 \pm 0,3$ & $0,7 \pm 0,04$ \\
\hline & 100 & $0,5 \pm 0,3$ & $0,8 \pm 0,7$ & $0,8 \pm 0,06$ \\
\hline \multirow{4}{*}{ Casca 2} & 25 & $0,5 \pm 0,3$ & $0,8 \pm 0,1$ & $0,7 \pm 0,06$ \\
\hline & 50 & $0,5 \pm 0,3$ & $0,9 \pm 0,2$ & $0,7 \pm 1,1$ \\
\hline & 75 & $0,8 \pm 0,08$ & $0,9 \pm 0,06$ & $0,8 \pm 0,04$ \\
\hline & 100 & $0,2 \pm 0,3$ & $1,7 \pm 0,2$ & $0,8 \pm 0,08$ \\
\hline \multirow{4}{*}{ Casca 3} & 25 & $0,5 \pm 0,3$ & $0,2 \pm 0,3$ & $0,5 \pm 0,3$ \\
\hline & 50 & $0,8 \pm 0,04$ & $0,3 \pm 0,4$ & $0,7 \pm 0,04$ \\
\hline & 75 & $0,8 \pm 0,04$ & $0,3 \pm 0,4$ & $0,8 \pm 1,1$ \\
\hline & 100 & $0,9 \pm 0,04$ & $0,2 \pm 0,3$ & $0,5 \pm 0,3$ \\
\hline \multirow{4}{*}{ Casca 4} & 25 & $0,5 \pm 0,3$ & $0,8 \pm 0,06$ & $0,7 \pm 0,04$ \\
\hline & 50 & $0,7 \pm 0,04$ & $0,9 \pm 0,04$ & $0,7 \pm 0,04$ \\
\hline & 75 & $0,2 \pm 0,3$ & $1,0 \pm 0,08$ & $0,5 \pm 0,3$ \\
\hline & 100 & $0,3 \pm 0,3$ & $1,03 \pm 0,1$ & $0,4 \pm 0,3$ \\
\hline \multirow{4}{*}{$\begin{array}{c}\text { Caroço } 4 \\
\text { hexano }\end{array}$} & 25 & - & $0,4 \pm 0,3$ & - \\
\hline & 50 & - & $0,9 \pm 0,04$ & - \\
\hline & 75 & - & $0,9 \pm 0,06$ & - \\
\hline & 100 & - & $0,9 \pm 0,04$ & - \\
\hline
\end{tabular}

Legenda: (-) não foi observada a formação de halo

Fonte: Dados da pesquisa.

Os testes com os extratos hexanólicos 1, 2 e 4 da polpa contra cepas de Klebsiella pneumoniae apresentaram resultados positivos em todas as placas testadas.

Os testes com extratos da casca da pupunha obtiveram resultados favoráveis para as cepas bacterianas utilizadas, pois todas as concentrações dos extratos apresentaram formação de halos nas placas. Todas as placas tiveram uma média considerável, com atividade antimicrobiana positiva, com resultados mais promissores do que as amostras da polpa testadas.

Porém as amostras 3 da casca apresentou uma atividade bactericida baixa em Staphylococcus aureus, quando comparada com os testes com Escherichia coli e Klebsiella pneumoniae.

Melhorança Filho e Pereira (2012), em ensaio microbiológico com a casca das duas espécies de pupunha (Bactris gasipaes Kunth e Bactris dahlgreniana Glassman) e de açaí (Euterpe oleracea), observaram a presença de formação de halo de inibição sobre Staphylococcus aureus nas primeiras 24 horas, porém foi observado que mesmo após 48 horas, permaneceu o efeito inibitório sobre $S$. aureus somente em óleos de açaí e de $B$. dahlgreniana, sem resultados positivos para $B$. gasipaes.

As variações na atividade antimicrobiana apresentada por extratos de plantas podem ser atribuídas a vários fatores: linhagem utilizada, processo de extração, seja pela diferença dos solventes utilizados ou pelo tipo de material vegetal (fresco ou seco); entre outros fatores (OSTROSKY et al., 2008).

Os resultados para as amostras dos extratos metanólicos e hexanólicos do caroço da pupunha em cepas bacterianas de Escherichia coli, Staphylococcus aureus e Klebsiella pneumoniae apresentaram resultados negativos, pois não apresentaram atividade microbiana a frente desses microorganismos, ocorrendo o crescimento microbiano em todas as placas testadas. Com exceção da amostra utilizando o extrato de hexano, que apresentou formação e inibição para Klebsiella pneumoniae, na concentração de $50 \mathrm{mg}$, faz-se necessário a repetição do ensaio para ter uma avaliação mais precisa.

Melhorança Filho e Pereira (2012) afirmam que o fato de B. gasipaes não apresentar formação de halo demonstra que o efeito antimicrobiano dos extratos não permanece por mais de 24 horas, podendo ser explicado por uma provável oxidação dos compostos ou volatilização dos mesmos. Sobre essa afirmativa, as atividades negativas de algumas amostras de extratos da pupunha testada podem estar relacionadas pela ocorrência da volatilização dos extratos.

Apesar dos resultados obtidos durante os testes, a atividade antimicrobiana dos extratos do fruto da pupunheira teve uma baixa atividade, porém estes testes apresentaram uma certa ação sobre os micro-organismos e se tem a necessidade de se realizar testes mais aprofundados com estas amostras.

\section{Conclusão}

Os extratos, obtidos pelo sistema Soxhlet, demostraram quem em condições adequadas e usando solventes de alta e baixa polaridade podem apresentar resultados promissores, em que as extrações obtiveram nove amostras de extratos de diferentes partes do fruto da pupunheira.

$\mathrm{O}$ efeito da atividade antimicrobiana das concentrações aplicadas dos extratos da pupunha apresentou baixa inibição nas concentrações testadas, diante os micro-organismos testados, porém os resultados são promissores. Considerando que substâncias naturais podem ser responsáveis pelo efeito da atividade antimicrobiana. Este estudo abre perspectivas para que novas investigações, envolvendo atividade antimicrobiana para extratos dos frutos da pupunheira amazônica. Para se avaliar com mais precisão, a ação antimicrobiana desses extratos, são necessários estudos mais aprofundados, identificando as substâncias responsáveis por inibir o crescimento bacteriano, realizando avaliação em outros micro-organismos. 


\section{Referências}

ARKCOLL, D.B.; AGUIAR, J.P.L. Peach palm (Bactris gasipaes H.B.K.), a new source of vegetable oil from the wet tropics. $J$. Sci. Food Agricul., v.35, n.5, p.520-526, 1984.

ALVES, E.G. et al. Estudo comparativo de técnicas de screening para avaliação da atividade antibacteriana de extratos brutos de espécies vegetais e de substâncias puras. Quím. Nova, v.31, n.5, p.1224-1229, 2008.

BIMAKR, M. et al. Comparison of different extraction methods for the extraction of major bioactive flavonoid compounds from spearmint (Mentha spicata L.) leaves. Food Bioproducts Proc., v.89, n.1, p.67-72, 2011.

BLOIS, M. Antioxidant determinations by the use of a stable free radical. Nature, v.181, p.1199-1200, 1958.

CAVALCANTI FILHO, J.R.N. Avaliação da atividade antimicrobiana e citotóxica de óleos essenciais extraídos de Buchenavia tetraphylla. Recife: UFPE, 2014.

CARVALHO, A.V. et al. Produção de snacks de terceira geração por extrusão de misturas de farinhas de pupunha e mandioca. Braz. J. Food Technol., v.12, n.4, p.277-284, 2009.

CARVALHO, A.V. et al. Características físicas e químicas de frutos de pupunheira no estado do Pará. Rev. Bras. Fruticul., v.35, n.3, p.763-768, 2013.

CÉO,L.V.A.; SILVA, M.G.C.;PINTO, S.S.Potencial de utilização do fruto da pupunheira (Bactris gasipaes Kunth) para produção de óleo. 2010. Disponível em: http://www.ceplac.gov.br/paginas/ pupunheira/download/CDTrabalhos/trabalhosSessoesPaineis/ Potencial\%20de\%20utiliza $\%$ C3\%A7\%C3\%A3o\%20da $\% 20$ pupunheira $\% 20$ (Bactris\%20gasipaes\%20Kunth) $\% 20$ para $\% 20$ produ $\%$ C3\%A7\%C3\%A3o $\% 20 \mathrm{de} \% 20 \% \mathrm{C} 3 \%$ B31eo $\% 20036-11$. pdf

CLEMENT, C.R. Pupunha (Bactris gasipaes Kunth, Palmae). Jaboticabal: Fundep, 2000.

COSTA, C.M.G.R. et al. Efeito inibitório do óleo essencial de manjericão sobre o crescimento in vitro de Erwinia carotovora. Tecnol. Ciênc. Agropec., v.3, n.3, p.35-38, 2009.

FIGUEIREDO, R.C.; ROCHA, W.C.; FREITAS, A.D.G. Efeito inseticida do óleo essencial e extratos etanólicos das folhas de mastruz (Chenopodium ambrosioides L.) sobre o gorgulho do milho (Sitophilus zeamais Mots). Ensaios Cienc., v.22, n.2, p.8084, 2018. doi: 10.17921/1415-6938.2018v22n2p80-84

GIORDANI, R. B. et al. Investigação do potencial antioxidante e anticolinesterásico de Hippeastrum (Amaryllidaceae). Química Nova, v.31, n.8, p.2042-2046, 2008.

LAROZE, L.; SOTO, C.; ZÚÑIGA, M. E. Phenolic antioxidants extraction from raspberry wastes assisted by-enzymes. Electr. J. Biotechnol., v.13, n.6, 2010.

LIMA, L.A.M. Avaliação química e biológica de extratos obtidos de espécies vegetais da flora amazônica como novos agentes antimaláricos. Manaus: UFAM, 2014.

MELHORANÇA FILHO, A.L.; PEREIRA, M.R. Atividade antimicrobiana de óleos extraídos de açaí e de pupunha sobre o desenvolvimento de Pseudomonas aeruginosa e Staphylococcus aureus. Bioscie. J., v.28, n.4, p.598-603, 2012.

NASCIMENTO, P. F. C. et al. Atividade antimicrobiana dos óleos essenciais: uma abordagem multifatorial dos métodos. Rev. Bras. Farm., v.17, n.1, p.108-113, 2007.
NODORI, R.O.; GUERRA, M.P. Biodiversidade: aspectos biológicos, geográficos, legais e éticos. In: SIMÕES, C.M.O. et al. Farmacognosia da planta ao medicamento. Porto Alegre: UFRGS, 2004.

OLIVEIRA, M.S.P.; COUTURIER, G.; BESERRA, P. Biologia da polinização da palmeira tucumã (Astrocaryum vulgare Mart.) em Belém-Pará, Brasil. Acta Bot. Bras., v.17 n.3, p.343-353. 2003.

OSTROSKY, E.A. Métodos para avaliação da atividade antimicrobiana e determinação da Concentração Mínima Inibitória (CMI) de plantas medicinais. Rev. Bras. Farm., v.18, n.2, p.301-307, 2008.

PINTO, T.J.A.; KANEKO, T.M.; OHARA, M.T. Controle biológico de qualidade de produtos farmacêuticos, correlatos e cosméticos. São Paulo: Atheneu, 2003.

RAMOS, A. Análise do desenvolvimento vegetativo e produtividade da palmeira pupunha (Bactris gasipaes Kunth) sob niveis de irrigação e adubação nitrogenada. Piracicaba: USP, 2002.

RESTREPO, J.; ESTUPIÑÁN, J. A.; COLMENARES, A. J. Estudio comparativo de las fracciones lipídicas de Bactris gasipaes Kunth (chontaduro) obtenidas por extracción soxhlet y por extracción con $\mathrm{CO} 2$ supercrítico. Rev. Col.. Quím., v.45, n.1, p.5-9, 2016.

ROCKENBACH, I. I. et al. Influência do solvente no conteúdo total de polifenóis, antocianinas e atividade antioxidante de extratos de bagaço de uva (Vitis vinifera) variedades Tannat e Ancelota. Ciênc. Tecnol. Aliment., v.28, p.238-244, 2008.

SANTO, M.L.E. et al. Cultivo da pupunha para produção de frutos no municipío de Coari-AM. Sodebras, v.8, n.90, p.1-5, 2013.

SÁNCHEZ-MORENO, C.; A procedure to measure the antiradical efficiency of polyphenols. J. Scie. Food Agricul., v.76, n.2, p.270- 276, 1998.

SILVA, R.S. et al. Óleo essencial de limão no ensino da cromatografia em camada delgada. Quím. Nova, v.32, n 8, p.2234-2237,2009.

SIMÕES, C.M.O. et al. Farmacognosia: da planta ao medicamento. Florianópolis: UFSC, 2007.

SODRE, L.E.A. Elaboração, avaliação físico-química, microbiológica e sensorial de doce de pupunha (Bactris gasipaes). Ariquemes: Universidade Federal de Rondônia, 2014.

SOLÓRZANO-SANTOS, F.; MIRANDA-NOVALES, M.G. Essential oils from aromatic herbs as antimicrobial agents. Curr. Opinion Biotechnol., v.23, p.1-6, 2011.

SOUZA, A.Q.L. et al. Atividade antimicrobiana de fungos endofíticos isolados de plantas tóxicas da amazônia: Palicourea longiflora (aubl.) rich e Strychnos cogens bentham. Acta Amazônica, v.34, n.2, p.185-195, 2004.

SUDAM. Rede para conservação e uso de recursos genéticos amazônicos. Grupo de Ciências e Tecnologia - Superintendência de Desenvolvimento da Amazônia. Belém: SUDAM, 1995.

YUYAMA, L.K.O.; COZZOLINO, S.M.F. Efeito da suplementação com pupunha como fonte de vitamina A em dieta: estudo em ratos. Rev. Saúde Pública, v.30, n.1, p.61-66, 1996.

ZUANAZZI, J.A.; MONTANHA, J.A. Flavonoides. In: SIMÕES, C.M.O. et al. Farmacognosia: da planta ao medicamento. Florianópolis: Editora UFSC, 2003. p.577-614. 